\title{
Anticomunismo a la chilena: el caso de James Bond en el cómic, 1959-1971
}

\author{
Anticommunism in Chilean Perspective: \\ The case of James Bond in comics, 1959-1971
}

Jorge Rojas Flores*

\begin{abstract}
Resumen
En este estudio caracterizamos dos adaptaciones chilenas de la serie James Bond, de Ian Fleming, en el formato de cómics, entre 1959 y 1971. La primera apareció en la revista Okey, y la segunda en 007 James Bond, ambas de la Editorial Zig Zag. El período escogido cubre dos fases de la Guerra Fría en un país periférico. Los resultados muestran distintos niveles de intensidad en los mensajes, así como cambios en la forma de representar la amenaza comunista. El esfuerzo de adaptación de una serie extranjera por parte de una empresa editorial revela el modo en que se reprodujo, con un énfasis local, las tensiones y consensos de este período.

Palabras clave: Guerra Fría, Chile, cómics, historietas, cultura de masas, James Bond.
\end{abstract}

\begin{abstract}
In this study we describe two Chilean adaptations of James Bond, Ian Fleming's serie, in comic format, between 1959 and 1971. The first one was published in Okey magazine, and the second one in 007 James Bond, both from Editorial Zig Zag. The period chosen covers two phases of the Cold War in a peripheral country. Outcomes show different levels of intensity in messages as well as changes in how to represent the communist threat. Adaptations of comics reveals how they reproduced, with local emphasis, tensions and consensus of this period.

Keywords: Cold War, Chile, comic, media culture, James Bond.

Introducción

La Guerra Fría expresó de múltiples formas la confrontación entre los dos bloques que dividían al Mundo, desde el diplomático y político institucional, hasta el social y cultural. Algunos autores han destacado este último como un campo de notable particularidad, que

\footnotetext{
* Chileno, académico de la Pontificia Universidad Católica de Chile. Este artículo es producto del Proyecto Fondecyt Regular $N^{\circ}$ 1130205, “Chile a través de las historietas, 1945-1960”. dirigido por el autor y patrocinado por la Universidad de Santiago de Chile (2013-2015). Correo electrónico: jorgerojasflores@gmail.com jrojaso@uc.cl Instituto de Historia, Pontificia Universidad Católica de Chile
} 
enfrentó iniciativas de todo tipo, en procura de la defensa simbólica de los dos proyectos en pugna. ${ }^{1}$ Como lo han planteado varios autores, esto no significó que la Guerra Fría Cultural fuera una mera reproducción mecánica de las lógicas políticas, ya que la forma en que cada sujeto y cada país se situó en este enfrentamiento tuvo matices especiales. ${ }^{2}$

En este artículo veremos la forma particular en que se vivió el clima de la Guerra Fría en la literatura de entretención de un país periférico, en particular en las adaptaciones para cómic de la serie de espionaje James Bond, publicadas en dos revistas distintas: Okey, entre 1959 y 1964, y 007 James Bond, entre 1968 y 1971. Nos interesa observar en estas versiones locales las diversas formas de intervención del contexto político, que en aquellos años fue experimentando cambios, tanto a nivel internacional como nacional.

En Chile el anticomunismo tuvo su propio recorrido y fue especialmente intenso bajo el gobierno de Gabriel González Videla (1946-1952). ${ }^{3}$ Sin embargo, la estabilidad política y cierto clima de tolerancia republicana permitieron que el enfrentamiento fuera relativamente moderado a partir de entonces, aunque el balance historiográfico no es homogéneo en este aspecto. Algunos autores plantean sus dudas sobre esta apariencia de estabilidad y tolerancia. ${ }^{4}$ Adicionalmente, algunas experiencias políticas latinoamericanas, como el peronismo, fueron gravitantes en incorporar otras alternativas, alterando de algún modo el esquema bipolar. En 1952, el Partido Comunista abandonó la clandestinidad y se reinsertó en el escenario político, aunque la tensión volvió a aumentar en la coyuntura electoral de 1964, y con mayor intensidad en 1970. La llegada al poder de Eduardo Frei en 1964 marcó una inflexión importante, que quedó reflejada en la apertura de relaciones diplomáticas con la URSS.

A nivel internacional, a partir de fines de los años 50, la Guerra Fría pasó a una fase distinta, tras el debilitamiento de la URSS como referente político y la aparición en escena de otros actores y nuevas preocupaciones, como la amenaza nuclear. Las intervenciones militares de Estados Unidos en Vietnam y Santo Domingo también generaron críticas y fisuras entre sus aliados, al ponerse en duda su convicción democrática. El fraccionamiento

\footnotetext{
${ }^{1}$ Rafael Pedemonte, "La 'diplomacia cultural' soviética (1964-1973)”, Bicentenario, 9.1 (2010), 57-100; Germán Alburquerque, La trinchera letrada. Intelectuales latinoamericanos y Guerra Fría, Santiago: Ariadna Ediciones, 2011; Karina C. Janello, "El Congreso por la Libertad de la Cultura: el caso chileno y la disputa por las "ideas fuerza" de la Guerra Fría", Izquierdas, 14 (dic./2012), 14-52; Adriana Petra, "Cultura comunista y Guerra Fría: los intelectuales y el movimiento por la paz en la Argentina", Cuadernos de Historia, 38 (junio/2013), 109-130.

${ }^{2}$ Benedetta Calandra y Marina Franco (eds.), La guerra fría cultural en América Latina. Desafíos y límites para una nueva mirada de las relaciones interamericanas, Buenos Aires: Biblos, 2012.

${ }^{3}$ Carlos Maldonado, ACHA y la proscripción del Partido Comunista en Chile, 1946-1948, Santiago: Flacso, marzo/1989; Carlos Huneeus, La Guerra Fría Chilena. Gabriel González Videla y la Ley Maldita, Santiago: Debate, 2009; Cristián Garay y Ángel Soto: Gabriel González Videla, No a los totalitarismos, ya sean rojos, pardo o amarillos, Santiago: Centro de Estudios Bicentenario, 2013.

${ }^{4}$ Juan Carlos Gómez Leyton, La frontera de la democracia. El derecho de propiedad en Chile 1925-1973, Santiago: Lom Ediciones, 2004; Marcelo Casals Araya, Anticomunismos, política e ideología en Chile: la larga duración de la "campaña del terror" de 1964, tesis de Magister en Historia, Pontificia Universidad Católica de Chile, Santiago, 2012.
} 
aumentó dentro la izquierda (dividida entre maoistas, titoistas, guevaristas, etc.), además de verse fortalecidas algunas posiciones reformistas, críticas tanto del capitalismo como del socialismo, como fueron en su momento los proyectos de Joao Goulart y Eduardo Frei, en Brasil y Chile respectivamente. En este contexto, la propia obra de Fleming comenzó a incorporar cambios, como lo ha estudiado en detalle Jeremy Black. La representación de la amenaza comunista se vio complementada por la aparición de otros peligros, en los libros más tardíos, además del permanente intento por reforzar el papel de Gran Bretaña, mostrándola con relativa autonomía frente a Estados Unidos y sus problemas. ${ }^{5}$

El libro que dio origen a la serie había sido publicada en inglés por primera vez en 1953 , bajo el título de Casino Royale, y desde entonces, anualmente fueron apareciendo sucesivos episodios, entre los cuales podemos mencionar Live and Let Die (1954), Moonraker (1955), Diamonds are Forever (1956) y From Russia, with Love (1957). ${ }^{6}$ En 1958, a raíz del éxito editorial, se inició la publicación de la versión para historieta, con frecuencia diaria (daily strip), dibujada por John McLusky y con guiones de Anthony Henry, Henry Gammidge y Peter O’Donnell. En 1962 se conoció la primera de varias adaptaciones para el cine. ${ }^{7}$

El rápido éxito de la serie, en sus distintos formatos, llamó la atención de los intelectuales interesados en los fenómenos propios de la cultura de masas, lo que llevó a la realización de algunos estudios sobre el personaje, desde variadas perspectivas. Proceso a James Bond, de Tornabuoni y otros autores, fue el pionero, en 1965, al que le siguieron varios más. ${ }^{8}$

Las investigaciones sobre el cómic surgieron en forma tardía, en parte por la subvaloración que predominó durante mucho tiempo en el campo académico, a pesar de los esfuerzos pioneros de autores como Humberto Eco. ${ }^{9}$ A nivel metodológico, las propuestas de Barker, McCloud y Muro coinciden en plantear ciertas particularidades en el lenguaje del cómic, así como en su desciframiento, que obligan a tener en cuenta tanto el texto (en globos y didascalias) como los aspectos visuales (encuadre, perspectivas, montaje, dibujo, etc.). ${ }^{10}$ Sin embargo, esta regla general debe tener en cuenta que el aspecto visual no adquiere igual

\footnotetext{
${ }^{5}$ Jeremy Black, The Politics of James Bond: From Fleming's Novels to the Big Screen, Westport: Praeger Publishers, 2001.

${ }^{6}$ Los títulos que aparecieron con posterioridad son Doctor No (1958), Goldfinger (1959), For your eyes only (1960), Thunderball (1961), The Spy who loved me (1962), On her Majesty's Secret Service (1963), You Only Live Twice (1964), The Man with the Golden Gun (1965) y Octopussy and The Living Daylights (1966)

${ }^{7}$ Para más detalles sobre las distintas versiones de la obra de Fleming, véanse las páginas web Archivo 007 y The Home of James Bond 007.

${ }^{8}$ Lietta Tornabuoni, y otros, Proceso a James Bond. Análisis de un mito, Barcelona: Editorial Fontanella, 1965; James Chapman, Licence to Thrill: A Cultural History of the James Bond Films, New York: Columbia University Press, 2000; Kalus Dodds, "Screening Geopolitics: James Bond and the Early Cold War films (1962-1967)", Geopolitics, 10.2 (2005), 266-289; Jeremy Black, "The Geopolitics of James Bond", Intelligence and National Security, 19.2 (Summer/2004), 290-303; y Black, The politics of James Bond.

${ }^{9}$ Humberto Eco, Apocalípticos e integrados en la cultura de masas, Barcelona, Ediciones Lumen, 1965.

${ }^{10}$ Martin Barker, Comics: ideology, power and the critics, Manchester/New York: Manchester University Press, 1989; Scott McCloud, Understanding Comics: The Invisible Art, Northampton: Kitchen Sink Press, 1993; Miguel Ángel Muro Munilla, Análisis e interpretación del cómic. Ensayo de metodología semiótica, Logroño: Universidad de La Rioja, 2004.
} 
connotación en todos los cómics. Como hemos explicado en otra parte, hay historietas especialmente intensas en incorporar componentes icónicos, lo que no parece suceder en particular en la versión inglesa de James Bond, que se publicó a partir de 1958, siendo algo más importante en la chilena, de $1968 .{ }^{11}$ Por problemas de espacio, no podremos desarrollar en forma intensa este aspecto.

Varios intentos por descubrir dimensiones políticas en las historietas nos han servido de modelo, como los de MacDougall y Murray, en los contextos de la Segunda Guerra Mundial y la Guerra Fría. ${ }^{12}$ En Chile, destacan los aportes de Jorge Montealegre y Maximiliano Salinas, para el caso de la caricatura política, además de nuestros estudios sobre Mampato, Chu-Man-Fú y varias otras series. ${ }^{13}$ El presente artículo aporta un componente nuevo, en contraste con estas obras. La dimensión política suele ser entendida únicamente desde su situación local, es decir, desarrollada por los autores (guionista y dibujante), en un contexto dado, acotado y fijo. Acá, en cambio, veremos un objeto cultural que surge en Inglaterra, circula por varios países, es traducido, adapta sus contenidos y en ocasiones incorpora elementos completamente nuevos, aunque siempre conservando una cierta afinidad con la obra original. El lugar de origen y recepción ya no coinciden, y además resulta difícil identificar el contexto de producción, que es a la vez local y global. Esta síntesis especial se puede ejemplificar con claridad en esta serie de espionaje. Adicionalmente haremos una comparación del resultado de esta adaptación en dos momentos distintos, lo que, esperamos, muestre evidencias de los cambios que experimenta el contexto nacional e internacional.

Para poder comparar las distintas versiones dibujadas de James Bond, utilizaremos la original inglesa, en particular la reedición facsimilar de Titan Books, además de las dos versiones chilenas, publicadas la primera en Okey y la segunda en 007 James Bond. Como el detalle de las diferencias y similitudes nos obligaría a dedicar mucho más espacio que el disponible, en el texto que sigue pondremos más acento a los elementos que distinguen a las dos adaptaciones realizadas en Chile, dejando la descripción de la serie original en manos de los autores que la han trabajado más detalladamente.

La versión publicada en Okey (1959-1964)

\footnotetext{
${ }^{11}$ Jorge Rojas Flores, Las historietas en Chile, 1960-1980. Industria, discursos y prácticas sociales, Santiago: Lom Ediciones, 2015 (en edición).

12 Robert MacDougall, "Red, Brown and Yellow Perils: Images of the American Enemy in the 1940s and 1950s", The Journal of Popular Culture, 32.4 (1999); Christopher Murray, Champions of the Oppressed? Superhero Comics, Popular Culture, and Propaganda in America During World War II, New Jersey: Hampton Press, 2011.

${ }^{13}$ Jorge Montealegre, Historia del humor gráfico en Chile, Lleida: Editorial Milenio, 2008; Maximiliano Salinas y otros, El Chile de Juan Verdejo. El humor político de Topaze, 1931-1970, Santiago: Editorial USACh, 2011; Jorge Rojas Flores, "Estrategias de poder y valores políticos en Mampato (1968-1978)", Mapocho, 71 (1er semestre/2012), 297-314; Jorge Rojas Flores, "Luchas políticas en una revista de historietas: Okey, 1949-1965", Cuadernos de Historia, 40 (junio/2014), 115-145; Jorge Rojas Flores y Mauricio García, "Humor, magia y política en El Diario Ilustrado: el caso de Chu-Man-Fú (1938-1950)", Mapocho, 76 (2do semestre/2014), 219-242.
} 
Un año después de publicada en el Reino Unido, apareció en Chile la serie "James Bond" en Okey. Como esta era una revista semanal, los episodios diarios fueron ajustados al formato de la publicación, lo que implicó algunas alteraciones en las viñetas y retoques en los dibujos, además de las adaptaciones propias de la traducción, que también eran realizadas por la editorial chilena. Lamentablemente, la ausencia de archivos de la empresa nos impide conocer a quienes participaron en estas tareas, así como los criterios que aplicaron. $^{14}$

Aunque, a primera vista, la versión en Okey fue idéntica a la inglesa, las diferencias eran importantes. En el aspecto visual, al parecer no hubo cambios significativos, como ocurrió con series recargadas de mayor erotismo y publicadas poco antes, que obligaron a aplicar retoques, para diluir estos rasgos. ${ }^{15}$ En James Bond, estos ajustes operaron únicamente bajo un criterio práctico, para ajustar el formato diario de la serie inglesa al de una revista. Como veremos, la función de los traductores parece haber sido más importante en este caso, posiblemente siguiendo alguna orientación editorial. Tal como lo han estudiado algunos expertos en el tema, la transferencia de un idioma a otro es más que un procedimiento técnico. También suele ser una actividad con ribetes políticos, donde lo que se dice y lo que se omite, así como la forma en que se elabora el relato, remite a un determinado contexto social y cultural. ${ }^{16}$

El primer episodio publicado en Chile fue "El bacarat de la muerte", adaptación de Casino Royale. La historia se concentra en Leon Burdet (en el original, Le Chiffe), agente soviético que en su calidad de tesorero de unos sindicatos franceses, realiza negocios por cuenta propia que le llevan a perder el dinero que se le ha encomendado. Bond está encargado de desenmascarar sus negocios, para destruir la organización a la que pertenece. Finalmente lo logra, lo que provoca que los propios soviéticos encarguen su asesinato y se desarticule la infiltración sindical ( $N^{\circ} 525-541$, agosto-dic./1959). Siguiendo la idea original de la novela de Fleming, la versión que apareció en Okey conservó la idea central de la historia: las sospechas gubernamentales sobre la acción de los sindicatos, vistos como meros instrumentos de los comunistas, algo que no solo afectaba a Francia (desde la perspectiva de los sectores anticomunistas), donde se ubica la escena, sino también a los países de la comunidad británica, a la cual pertenecía el autor. ${ }^{17}$

\footnotetext{
${ }^{14}$ Esto explica que la fuente principal para esta investigación haya sido la revista, sin poder complementarla con otras.

${ }^{15}$ Fue el caso de "Pantera Rubia", entre 1952 y 1959. Al respecto, Rojas, "Imágenes de la mujer en Okey, 1949-1965", inédito.

${ }^{16}$ Para el caso chileno hay pocos estudios sobre el tema, desde una perspectiva histórica y política. Una excepción es el interesante texto de Payás sobre el papel de los traductores en el siglo XIX y comienzos del $\mathrm{XX}$, y Estefane, sobre el desafortunado intento de Vendel-Heyl por traducir a un polémico autor clásico, Lucrecio, en un ambiente conservador como el chileno. Gertrudis Payás, "La Biblioteca Chilena de Traductores, o el sentido de una colección”, en Biblioteca chilena de traductores ordenada por José Toribio Medin (2da edición, Santiago: Dirección de Bibliotecas, Archivos y Museos, 2007) 23-68; Andrés Estefane, "De naufragios e infortunios. Louis Antoine Vendel-Heyl en Chile", en Juan Luis Ossa y otros, XIX Historias del siglo diecinueve chileno, Santiago: Ediciones B, 2006, 71-98.

${ }^{17}$ Recordemos que Fleming era inglés, aunque la obra fue escrita en Jamaica. En todo caso, el contexto de referencia parece haber sido Gran Bretaña, que el autor siguió visitando tras su traslado a la isla caribeña.
} 
En la versión publicada en Chile, las referencias a los soviéticos son evidentes, aunque hubo especial cuidado de moderar las alusiones directas. Como ocurrió también en otros episodios, con frecuencia se habla de una "potencia extranjera", en vez de hacer mención directa a la Unión Soviética, siguiendo la versión inglesa. ${ }^{18}$ En todo caso, no es difícil percibir que el tono es fuertemente antisoviético. Además, en ocasiones, no se elude mencionar en forma explícita a los "amos soviéticos" (№539, 4/dic./1959). Es posible que, en la época, la revista considerara inapropiado para el público chileno leer un texto con excesivas referencias anticomunistas.

En esta primera obra de Fleming, el protagonista todavía no se perfila como un agente indestructible, algo que se mantiene en la versión publicada en Okey en 1959. De hecho, el desenlace resulta inesperado, porque Bond se salva de las torturas de Le Chiffe gracias a la intervención del agente soviético, quien ha sido enviado para matarlo. El final, además, es bastante oscuro, porque se devela que Marcia, su aliada en la misión, es una doble espía. Temerosa de ser descubierta, se suicida, dejando una nota explicativa a Bond. El contenido es especialmente trágico porque Bond pensaba casarse con ella.

Los siguientes episodios tuvieron similar tono conspirativo y anticomunista, aunque el lenguaje fue ligeramente moderado en la versión chilena. En "Contraespionaje" (basada en Live and Let Die), la acción se traslada a Estados Unidos, donde Bond desbarata una organización que financia el espionaje en ese país. El villano es Mr. Big quien en forma deliberada utiliza el vudú "para obtener el control absoluto en el barrio de Harlem, primero como gangster y luego como agente secreto de la potencia extranjera que lo tiene a sueldo" ( $\mathrm{N}^{\circ} 542,25 /$ dic./1959). Nuevamente se aprecia el intento por evitar una referencia directa a los comunistas, ya que el texto original aludía a su condición de "agente soviético" (imagen $\mathrm{N}^{\circ}$ 1). En el siguiente episodio, bajo el título de "Vendetta" (basada en Moonraker), el enemigo es un magnate, Sir Drax, un ex nazi, que conspira contra Inglaterra aliándose con los rusos, aunque nuevamente se hacen comunes los eufemismos en la adaptación local (N553-566, marzo-junio/1960). Una excepción resulta el episodio "Gemas de color de sangre", donde esto no es necesario, porque se diluye la amenaza comunista ( $\mathrm{N}^{\circ} 587-604$, nov./1960-marzo/1961). Esta historia marca una pausa en la obra de Fleming (aunque el tema volverá a aparecer más adelante), en una época en que el anticomunismo abierto y simple ya comienza a agotarse como tema, incluso en las novelas de espionaje, como ocurría por entonces en las obras de John Le Carré. ${ }^{19}$

\footnotetext{
Black, The Politics of James Bond.

${ }^{18}$ Por ejemplo, el narrador explica que Burdet es "enviado de una potencia extranjera, enemiga del mundo Occidental" (N525, 28/agosto/1959).

${ }^{19}$ En 1961 apareció la primera obra de John Le Carré, Call for the Dead, de tono sombrío y cruzado por dilemas morales.
} 


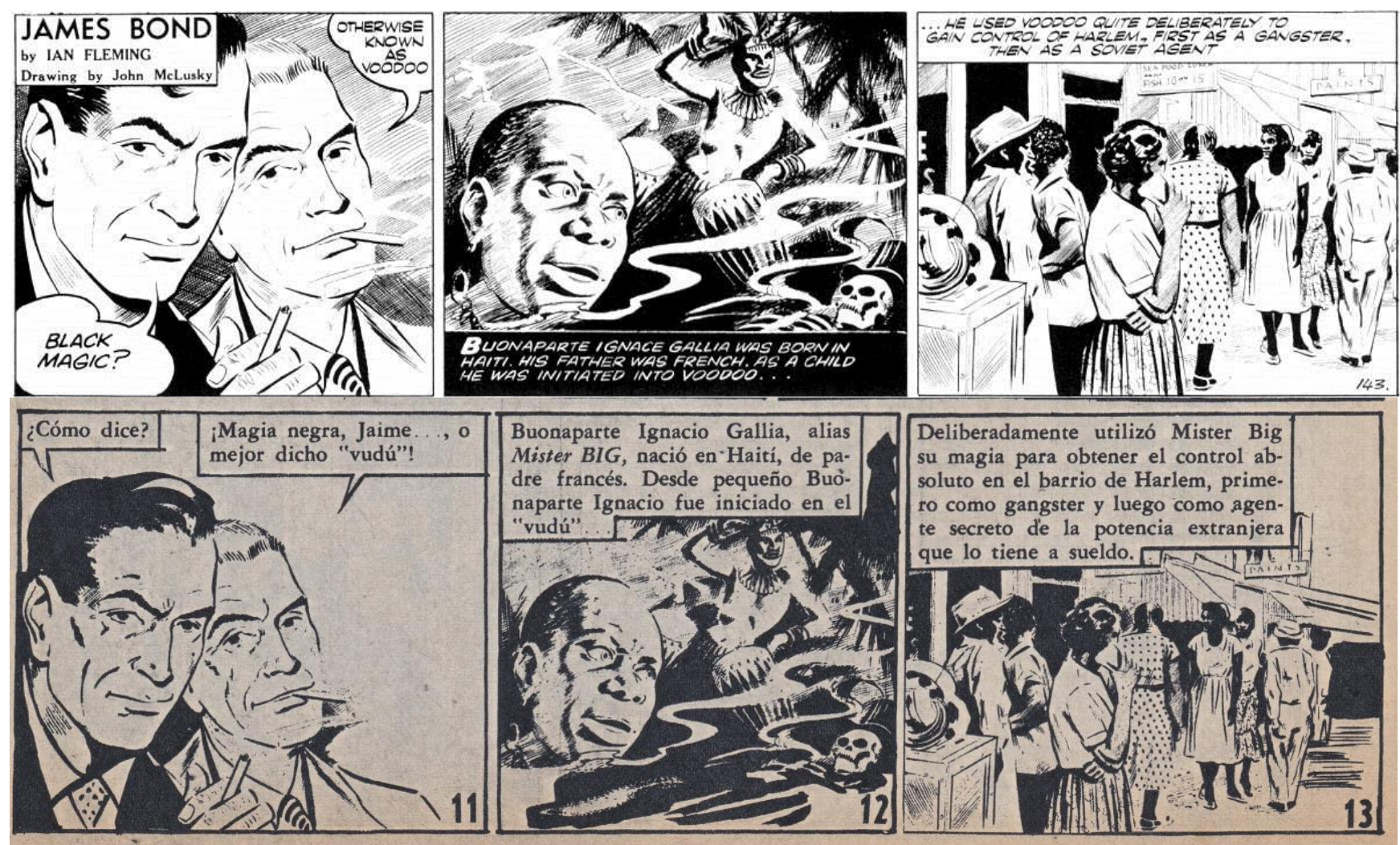

Imagen N¹: Original de "Live and Let Die" (1958), tira 143, y versión publicada en Okey, N542, 25/dic./1959. Guión adaptado de Anthony Hern y dibujos de John McLusky. Traductor y retocador desconocidos.

El tono antisoviético se retoma en "Entre espías anda el juego" (basada en From Russia with love). En este caso, no hay dudas sobre el origen de todos los males, por el dibujo, el contexto, los nombres utilizados y las continuas referencias a "camaradas". Sin embargo, en Okey se insiste en evitar una referencia directa a la Unión Soviética, a diferencia del original $\left(\mathrm{N}^{\circ} 605-617\right.$, marzo-junio/1961). En la versión inglesa se menciona la ubicación real del cuartel general de Smersh ("Inside the headquarters of Smersh on the Sretenka Ulitsa in Moscow", strip 495), mientras la traducción realizada en Chile fue bastante elusiva ("Entre tanto en los cuarteles del servicio de contraespionaje de la potencia extranjera...", $\left.\mathrm{N}^{\circ} 605,10 / \mathrm{marzo} / 1961\right)$. En el siguiente episodio esto cambia. El Doctor Shang es un desquiciado oriental aliado de los "rusos", quienes son mencionados sin eufemismos ( $\left.\mathrm{N}^{\circ} 659,23 / \mathrm{marzo} / 1962\right)$. Sus instalaciones ponen en riesgo a Estados Unidos al interferir los proyectiles de prueba que estos lanzan. En "Misión en Roma" (originalmente "Risico", de 1960), la historia se centra en un traficante de droga, que está envenenando a la juventud inglesa. Nuevamente se omite la referencia directa. Kristatos, el villano, obtiene gratuitamente el opio que le proporciona "una potencia enemiga interesada en destruir a Inglaterra desde su base: ¡la juventud!" (N736, 13/sept./1963).

En "Estrictamente confidencial" (originalmente "For your eyes only", novela publicada en 1960) no se trata de una misión de espionaje, sino un ajuste de cuentas personal, que M le 
encarga a Bond (N745-757, nov./1963-febr./1964). El enfrentamiento entre las potencias vuelve a desaparecer. En esta ocasión el villano es un gangster que espera proteger sus intereses mientras se estabiliza la situación de su país. Aunque en el cómic inglés se alude directamente a la transición entre la caída de Batista y el ascenso de Castro, en la versión chilena esta circunstancia es descrita en forma elíptica: "vienen de una isla en la cual pronto caerá un dictador para ser reemplazado por otro...”. (N745, 15/nov/1963). ${ }^{20}$

Un elemento común en la serie, que se mantendrá en la adaptación que veremos a continuación, fue el énfasis en las conspiraciones y el control de pequeños grupos. Los movimientos sociales, cuando llegan a aparecer, no son más que el resultado de maquinaciones al servicio de infiltrados y agentes extranjeros.

Como vimos, el sesgo político de la serie inglesa se moderó parcialmente por efecto de la traducción, que disminuyó la frecuencia con que se utilizaron las expresiones anticomunistas. A ello se agregó una circunstancia particular: en Okey no solo circularon estos contenidos. En ella hubo también espacio para series de contenido romántico, suspenso policial y aventuras de todo tipo. Algunas de ellas incluso llegaron a mostrar simpatías por la causa republicana en España y por la intervención soviética durante la Segunda Guerra Mundial, o plantearon críticas al colonialismo. ${ }^{21}$ La publicación, por tanto, no tenía una orientación monolítica, por lo menos en los años 50, en la etapa más dura de la Guerra Fría, y su público lector parece haber sido variado.

La versión publicada en 007 James Bond (1968-1971)

Okey dejó de publicarse en 1965, por entonces convertida en una revista exclusivamente de vaqueros. La industria del cómic había experimentado cambios y la publicación no había logrado ajustarse al nuevo formato dominante, con impresión a todo color y episodios unitarios y conclusivos. Siguiendo la tendencia, Zig Zag comenzó a privilegiar la publicación de nuevos títulos, poniendo énfasis a los contenidos temáticos, con revistas bélicas, de vaqueros, de aventuras en la selva y de espionaje. ${ }^{22}$

Esta etapa se inició en 1962 con la firma del acuerdo con Disney, que permitió una base material para contratar un equipo de dibujantes, diagramadores, coloristas y traductores, que comenzaron a editar Disneylandia y, dos años después, Aventuras Disney, que incluyó la serie "El Zorro", un producto híbrido con contenidos extranjeros y algunos locales. En 1965 se comenzaron a ensayar proyectos enteramente nacionales, como Rocket, de ciencia ficción, y El Jinete Fantasma, pero fuertemente influidas por estilos y contenidos de sus modelos europeos y norteamericanos. La vinculación entre lo global y lo local ya empezaba a ser más compleja, en comparación con la experiencia de Okey, en general limitada a

\footnotetext{
${ }^{20}$ El original dice: “Cuba's riddled with crooks and gangsters. They want to get out before Batista falls and Castro gets in" (strip 990).

21 Más detalles en Jorge Rojas Flores, "Tiranías, luchas políticas y justicia en una revista chilena de historietas: Okey, 1949-1965" (inédito).

${ }^{22}$ Un completo catastro de estas revistas en Moisés Hasson, Comics en Chile. Catálogo de revistas (19082000), NautaColecciones Editores, Santiago, 2014.
} 
reproducir series extranjeras (salvo "Condorito" y unas pocas más), con ligeras modificaciones locales.

Como ya vimos, el ambiente social y político se hacía cada vez más exaltado y los cambios en los códigos morales eran notorios. Adicionalmente las propuestas reformistas buscaban desmarcarse de la polaridad cerrada de los años 50, sin lograrlo plenamente. El propio anticomunismo adquirió ribetes mucho más diferenciados y complejos, con la aparición del "titoismo", el "maoismo" y el "guevarismo", por citar algunos ejemplos. ${ }^{23}$ Todas estas condiciones propias del ambiente tardío de la Guerra Fría se filtraron en las publicaciones de aquellos años.

En 1968, la Editorial Zig Zag comenzó a publicar un nuevo título, entre los muchos que editaba: 007 James Bond. Su éxito fue inmediato, transformándose en una de las que exhibió el mayor tiraje, cerca de 70 mil ejemplares quincenales. A diferencia de la anterior versión, la producción de esta revista quedó a cargo de Germán Gabler, del Departamento de Historietas, quien adaptó directamente las novelas de Fleming, creando también episodios completamente inéditos. Al parecer, el convenio con la empresa poseedora de los derechos contemplaba esta mayor libertad para crear historias adicionales, preservando el estilo de la serie. Los dibujos quedaron en manos del propio Gabler, además de Abel Romero, Hernán Jirón y Lincoln Fuentes, entre otros. Aunque hubo variantes notorias en los estilos, algo propio de la constante presión por trabajar en varias revistas a la vez y dar cabida al personal disponible, todos ellos intentaron explotar la estética cinematográfica de la serie, abundante en acción, que ya obtenía un resonado éxito con ayuda de la atractiva figura de Sean Connery. ${ }^{24}$ De ahí que el contraste con la versión aparecida en Okey sea notorio: la nueva estética se aprecia mucho más atractiva, el contenido más centrado en la acción y las referencias políticas más tenues.

Si observamos los componentes visuales, la versión chilena de los años 60 estuvo dominada por mujeres con escasa ropa, en insinuantes bikinis o ropa ajustada, además de escenas de alcoba, aunque nunca explícitas, para evitar algún reproche moral. También se multiplicaron las viñetas dedicadas a la acción, con enfrentamientos de todo tipo.

En 007 James Bond las variadas misiones que se le encomiendan al protagonista suelen tener un trasfondo político, donde la lucha contra el comunismo es central, aunque no con la misma intensidad de la versión aparecida en Okey. Esto se debió, en parte, a que fueron incluidos más episodios de Ian Fleming, quien fue ampliando las temáticas y el perfil de los antagonistas al avanzar la década de los 60, hasta su muerte en $1964 .{ }^{25}$ Además, al basarse directamente en la obra original, el guionista chileno desarrolló algunas historias laterales que no siempre tenían como centro la amenaza comunista.

\footnotetext{
${ }^{23}$ Recordemos que Tito fue recibido por Jorge Alessandri, en 1963.

${ }^{24}$ Sobre la revista, algunos datos en Rojas, Las historietas en Chile, 1960-1980; y Mauricio García, “Germán Gabler" (entrevista), disponible en el sitio web Ergocomics: http://ergocomics.cl/wp/2003/11/germn-gabler/.

${ }^{25}$ Un ejemplo en este sentido es The spy who loved me, novela de 1962, narrada por una joven que se encuentra fortuitamente con Bond. Fue publicada en la revista 007 James Bond en abril de $1970\left(\mathrm{~N}^{\circ} 36\right)$.
} 
En las primeras novelas el enemigo es Smersh, de origen soviético. Spectre fue apareciendo con mayor frecuencia a partir de 1961 (por primera vez, en la novela Thunderball), desplazando a las organizaciones vinculadas a la URSS, aunque sin desaparecer del todo. La función de Spectre es menos clara en términos políticos, en la medida en que es descrita como una institución internacional dedicada al crimen organizado, sin objetivos definidos. Así aparece descrita en la revista chilena en 1968, donde su objetivo es matar por encargo a un gobernante ("Spectre", N 28, 28/nov./1969), y luego robar un avión con una carga atómica para chantajear a varios países ("Operación trueno", No33, 5/febr./1970). En "El espía que me amó" ( $\left.\mathrm{N}^{\circ} 37,3 / \mathrm{abril} / 1970\right)$, los rusos contratan a Spectre para que asesine a un científico de Alemania Oriental que ha desertado y entrega valiosos secretos.

En algunos relatos de Fleming la amenaza a la seguridad de Inglaterra es indirecta, sin enemigos claros. Así ocurre en "Operación riesgo" (originalmente Risico), episodio en el que James Bond debe detener a una asociación ilegal dedicada al contrabando de heroína. La operación sigue teniendo importancia estratégica, porque se sospecha que detrás de ella hay un intento por destruir las "reservas morales y físicas" de Inglaterra por medio de una especie de "sabotaje sicológico" ( $\mathrm{N}^{\circ} 1,4 /$ nov./1968). En este caso, no hubo mayores diferencias de contenido con la versión anterior publicada en Okey. En la revista se agregaron varias historias similares, donde las misiones aparentan tener un fin económico, resolver robos que involucran grandes volúmenes de dinero, aunque en verdad detrás de ellos hay conspiradores e intentos de desestabilización política. ${ }^{26}$ Una historia con baja connotación política es "La rareza Hildebrand", aunque la circunstancia fortuita que lleva a Bond a las islas Seychelles es detectar los posibles alcances de una "infiltración subversiva desde Ceilán”, consistente en huelgas y sabotajes $\left(\mathrm{N}^{\circ} 2,15 /\right.$ nov./1968). ${ }^{27}$

La tendencia a omitir algunas referencias explícitas a los soviéticos, que ya se había aplicado en la versión de Okey, se mantuvo en la nueva revista. En "Sabotaje" (basada en "Moonraker") la relación con los comunistas es evidente, pero se encubre bajo alusiones a "camaradas" y "amigos de oriente" ( $\left.\mathrm{N}^{\circ} 18,11 / \mathrm{julio} / 1969\right)$. En varios relatos sucesivos el personaje que está detrás es Goldfinger, tesorero de Smersh, es decir, nuevamente se trata de un agente soviético, pero la vinculación no se desarrolla con detalle y la preocupación central es la acción ( ${ }^{\circ} 10-14$, marzo-mayo/1969). Lo mismo sucede con Le Chiffe, el protagonista de "Casino Royale", descrito como personaje clave dentro de Smersh y cerebro de algunos robos, en varios relatos previos al principal. En uno de ellos sólo se habla de la presencia de una "siniestra organización" ( ${ }^{\circ} 5,30 /$ dic./1968) ${ }^{28}$

Hay episodios como "De Rusia con amor" donde la intervención de las autoridades soviéticas es directa. En una reunión el general Gruchenko, a cargo de Smersh, señala: "Creo, y con ello expreso el sentir del camarada Primer Ministro, que la única manera de

\footnotetext{
${ }^{26} \mathrm{~N}^{\circ} 12 ; 13 ; 14 ; 23 ; 38$ y 39 , de abril/1969 a mayo/1970.

${ }^{27}$ Lo mismo sucede en "Solo para tus ojos", centrada en una operación encargada por M para vengar la muerte de una pareja conocida ( $\mathrm{N}^{\circ} 3,6 /$ dic./1968).

${ }^{28}$ Hay referencias a Le Chiffe en los $\mathrm{N}^{\circ} 4,6$ y 7 (dic./1968 a enero/1969).
} 
salvar nuestro prestigio es realizar una acción de terrorismo que produzca conmoción a través del mundo" (N²2, 5/sept./1969).

Sin embargo, el tono anticomunista tendió a ser más moderado y los dilemas personales del protagonista se diluyeron. En este sentido, la versión chilena de Casino Royale, de 1969, se distanció de la inglesa, publicada una década antes en Okey. El final trágico fue simplemente eliminado. La hermosa Vesper Lynd no es una contraespía ni se suicida. Al contrario, Bond y ella terminan juntos, en un idilio fugaz, como muchos en la serie $\left(\mathrm{N}^{\circ} 8\right.$, 12/febr./1969). Gran parte de la trama, en este y otros episodios, se dedica a seguir la acción del protagonista, quien parece más entusiasmado con la aventura y las mujeres, que con la defensa de la libertad y la democracia. Las versiones para el cine, muy populares en los años 60, fueron decisivas en este énfasis.

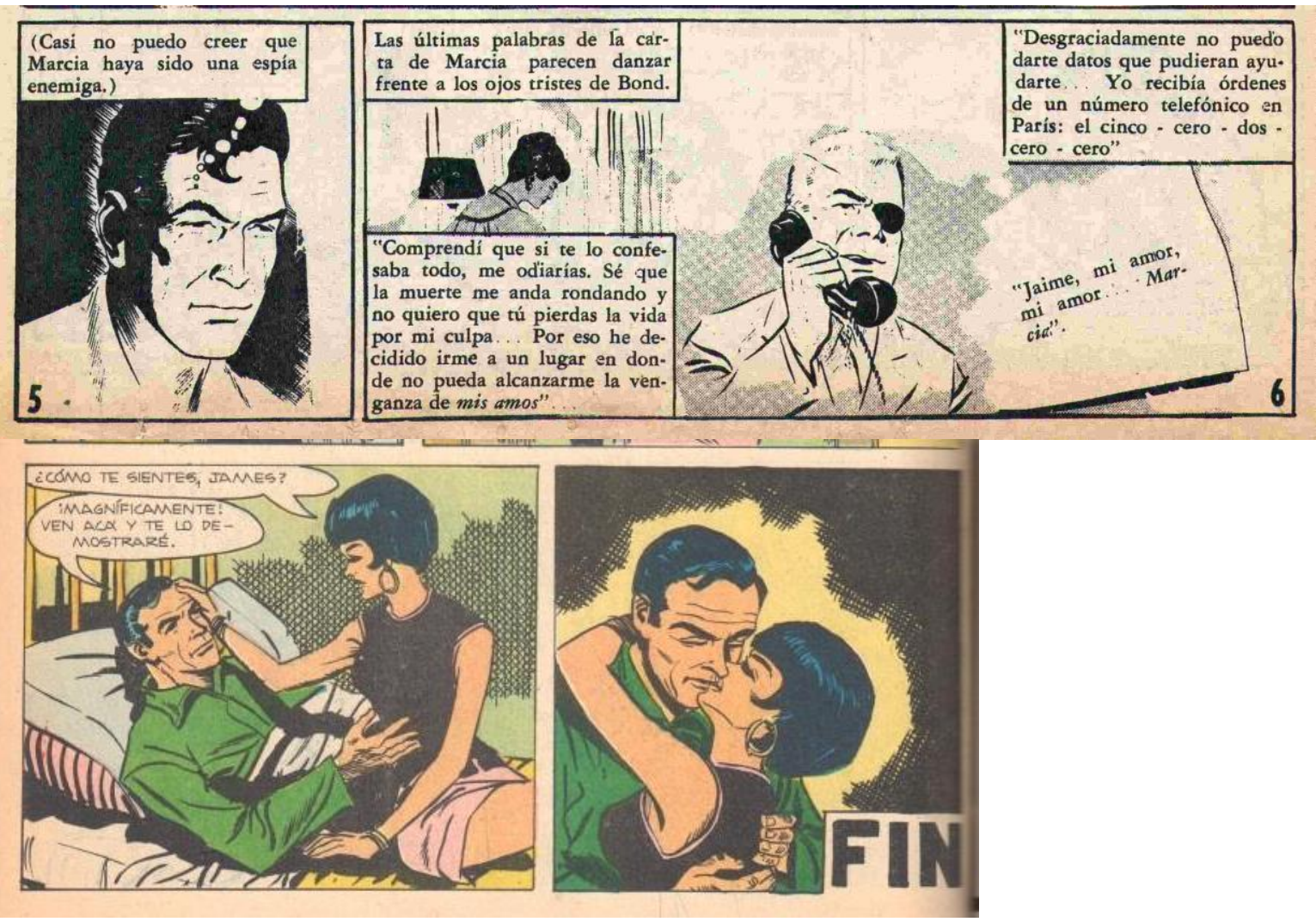

Imagen $\mathrm{N}^{\circ}$ 2: Dos finales para un mismo episodio, "Casino Royale". Arriba, la versión trágica en Okey, N541, 18/dic./1959. Abajo, desenlace más liviano en 007 James Bond, $\mathrm{N}^{\circ} 8,12 /$ febr./1969.

En la revista 007 James Bond no solo se dibujaron guiones extranjeros, basados en las novelas de Fleming, sino que se ilustraron versiones enteramente chilenas, escritas por Germán Gabler. La razón parece haber sido estrictamente económica. ${ }^{29}$ Sabemos que este

\footnotetext{
${ }^{29}$ En las revistas extranjeras que resultaban exitosas se solían agregar episodios propios, para poder mantener la entrega regular (los originales a veces tardaban mucho) e incluso prolongarla cuando se agotaban los
} 
dibujante y guionista siempre mantuvo cierta distancia con las ideas de izquierda. ${ }^{30}$ En todo caso, este elemento no debió ser decisivo, ya que su autonomía para crear tenía límites, debiendo mantener cierta fidelidad con la serie inglesa. De todos modos, estos episodios reflejaron con mayor fuerza el contexto local de la época, aunque siempre situando la acción en otros países.

En varios guiones chilenos se mantuvo la idea original, de tono marcadamente anticomunista. En "Juego de niños" un grupo de enanos, vinculados a un circo búlgaro, son contratados por una "potencia oriental" para matar al Primer Ministro británico ( $\mathrm{N}^{\circ} 7$, 30/enero/1969). En "Safari mortal", Bond debe descubrir las razones que tiene un país africano para aliarse con potencias del este, a pesar de ser un tradicional amigo de Occidente ( $\left.\mathrm{N}^{\circ} 19,24 / \mathrm{julio} / 1969\right)$. En "El asunto CIPET", tiene que investigar una organización política que busca devolver Hong Kong a China comunista $\left(\mathrm{N}^{\circ} 24\right.$, 2/oct./1969). Por su parte, en "El rally de la muerte", el enemigo es un gobierno de Europa Oriental (al parecer Albania) que persigue a la disidencia (N57, 22/febr./1971).

En grado creciente, en los episodios chilenos (sobre todo aquellos que aparecieron en 1970) se agregaron temas y personajes nuevos. Por ejemplo, en "La reina de las abejas" el peligro queda encarnado en una feminista radical que ha creado una sociedad donde los hombres son tratados como esclavos sumisos ( $\mathrm{N}^{\circ} 29,16 /$ dic./1969). También se sumó la temática latinoamericana en "Grito de libertad", ambientada en un país caribeño, donde un cruel y corrupto dictador enfrenta una guerrilla apoyada por Inglaterra. El dictador chantajea con un agente inglés que ha capturado, a cambio de ayuda que ni rusos ni norteamericanos quieren entregarle ( $\left.\mathrm{N}^{\circ} 45,24 \mathrm{julio1970}\right)$. Adicionalmente se hacen presente grupos paramilitares al servicio de gobiernos agresores, sin que se planteen vínculos con la izquierda ("Mercenarios", N53, 12/nov./1970), así como delincuentes comunes, motivados por la codicia ("El príncipe y el dragón”, $\mathrm{N}^{\circ} 47,12 /$ agosto/1970). Un caso interesante se produce en el episodio en el que Bond debe proteger a un cruel gobernante árabe, con muchos enemigos, pero aliado de Inglaterra, que está de visita en este último país. La oposición no es descrita en forma positiva y más bien se enfatiza que se trata de un país rico en petróleo, pero sumido en agudos conflictos de poder. Finalmente Bond logra evitar varios atentados, aunque se sugiere que nada evitará que el tirano muera una vez concluida la misión (imagen $\mathrm{N}^{\circ} 3$ ). Como en otros episodios de esta etapa, la función del espionaje se diluye y se limita al cumplimiento de tareas de dudoso valor moral. Posiblemente el contexto político (campaña presidencial y ascenso al poder de Allende) estaba influyendo en el contenido de la revista, cuyo equipo evitaba sumarse al clima ya polarizado, incorporando nuevos temas. ${ }^{31}$

originales. También pudo influir el interés de los propios guionistas y dibujantes.

${ }^{30}$ En Quimantú, donde comenzó a trabajar en 1971, no se sintió a gusto y dejó la empresa, como se revela en una entrevista realizada por Mauricio García, "Germán Gabler”, disponible en:

http://ergocomics.cl/wp/2003/11/germn-gabler/

${ }^{31}$ La falta de archivos de la editorial impide aclarar si se trata de una estrategia de la empresa, de una decisión de los equipos de producción o de una tendencia derivada del ambiente de la época. 

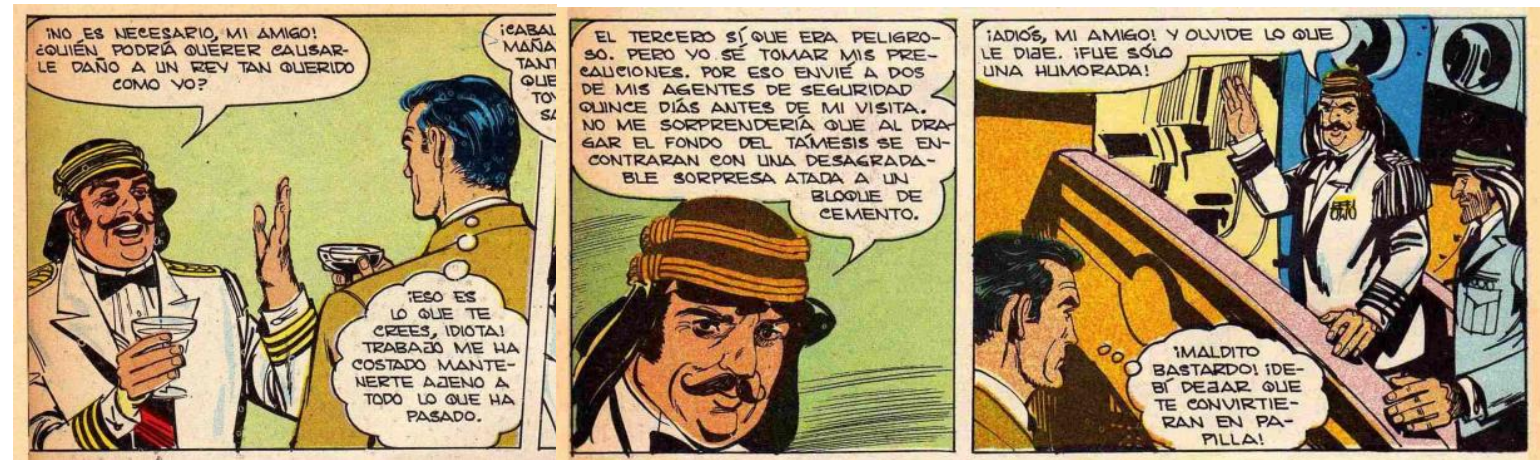

Imagen $N^{\circ}$ 3: Bond protege a un dictador, en "Guardaespaldas", en 007 James Bond, $\mathrm{N}^{\circ} 49$, 17/sept./1970. Dibujos de Lincoln Fuentes, guión de Germán Gabler.

En los últimos episodios, la versión chilena agregó un personaje nuevo, El Hombre sin Rostro. Al comienzo el personaje actúa misteriosamente, y sólo se sabe que no se trata de un agente soviético. Al develarse el secreto, nos enteramos que es un antiguo terrateniente de una excolonia africana, movido por el deseo de venganza contra Inglaterra, tras otorgar independencia a sus posesiones (N54, 26/nov./1970). Su perfil es el de un racista defensor de la superioridad de los colonos blancos, diluyéndose el típico antagonismo propio de la Guerra Fría.

En los episodios finales, con guión de Gabler, es posible observar más cambios en la serie, como la tendencia a humanizar al enemigo, por lo menos en algunos personajes. En "La mano del destino", hace su aparición un espía ruso de aspecto bonachón. Dimitri Prochenko es la antítesis de Bond (de edad más avanzada, algo desgarbado, sin mucha agilidad física), aunque igualmente eficiente en su labor. Tanto Bond como Prochenko deben proteger a un criminal nazi amenazado por una "organización terrorista hebrea", con el fin de que trabaje para sus respectivos países. M justifica la misión, en un tono pesimista: "Este es un mundo sucio y no vale la pena desvelarse por las cosas que suceden en él”. Al final del episodio, el nazi se suicida, atormentado por sus propios miedos. Al despedirse, Bond le desea suerte a Prochenko, aunque sabe que están en trincheras opuestas. Pareciera que cada cual hace el trabajo que le ha correspondido (imagen $\mathrm{N}^{\circ} 4$ ). Más adelante vuelve a aparecer apoyando a Bond, para evitar un conflicto diplomático entre rusos y norteamericanos $\left(\mathrm{N}^{\circ} 46\right.$, 10/agosto/1970); disputan el secreto de un arma bacteriológica que le ha sido robada a los chinos, aunque finalmente colaboran para que no caiga en poder del Hombre Sin Rostro (No50, 2/Oct./1970); y unen fuerza contra Spectre (N59, 16/marzo/1971).

En una década marcada por crecientes contactos entre los países bajo la esfera de influencia norteamericana y los países socialistas (por ejemplo, a través de embajadas culturales), negociaciones y eventualmente alianzas entre los países capitalistas y algunos socialistas (por razones geopolíticas, a veces para aislar a la Unión Soviética, como ocurrió con Yugoslavia), no deben extrañar estos acercamientos. Es la época, además, de la política de Coexistencia Pacífica de la URSS, que levantó sospechas pero también expectativas.

Los episodios de distensión, dentro del contexto de Guerra Fría, claramente influyeron en 
las series de espionaje. En algunas se consideró la alianza entre países occidentales y la Unión Soviética para detener a enemigos comunes. Fue lo que ocurrió en la serie de televisión El agente de Cipol (The man from Uncle), coprotagonizada por un norteamericano (Napoleon Solo) y un ruso (Illya Kuryakin), exhibida originalmente entre 1964 y 1968. A partir de 1965 se agregó una sátira al género del espionaje, El Superagente 86 ("Get Smart"), protagonizada por Don Adams como Maxwell Smart, la que fue transmitida por la naciente televisión chilena. En ella, ni siquiera hay claridad sobre el perfil ideológico de los villanos, quienes no son asociados a los soviéticos, sino a una organización siniestra y terrorista, pero de rasgos ridículos, vinculada más bien al nazismo.

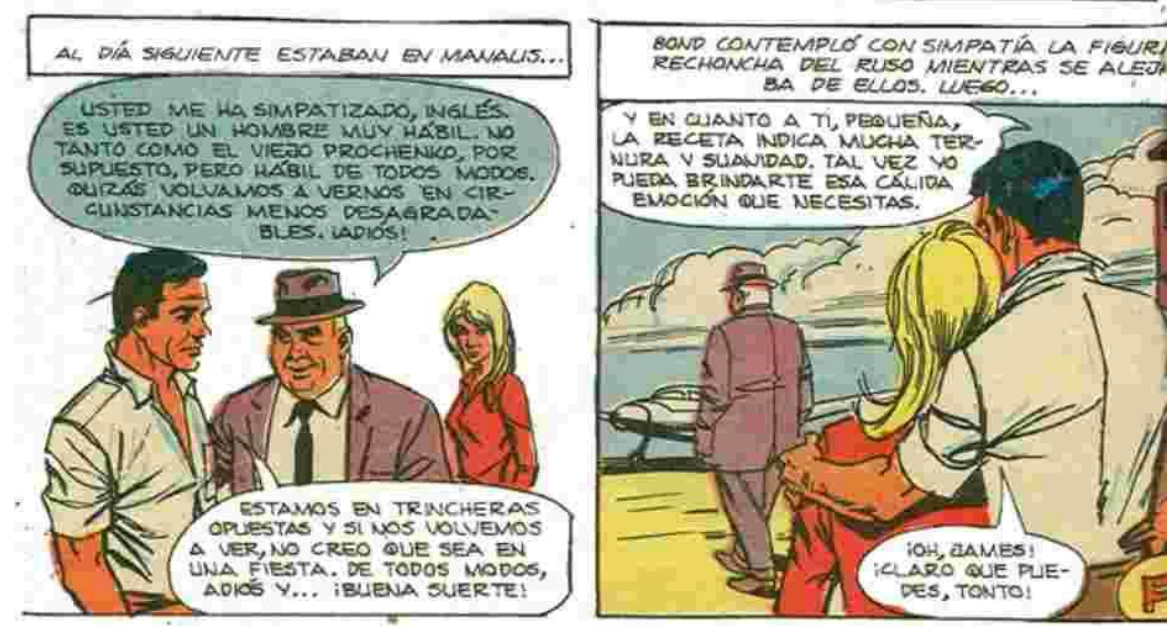

Imagen $\mathrm{N}^{\circ} 4$ : Un ruso bonachón, escena final del episodio chileno "La mano del destino" en 007 James Bond, $N^{\circ} 32,15 /$ enero/1970. Dibujos de Abel Romero y Manuel Rojas, guión de Germán Gabler.

La humanización del enemigo comunista y la pérdida relativa de centralidad del antagonismo propio de la Guerra Fría posiblemente estuvo influida por el ambiente que vivía el país, en plena campaña electoral, que llevaría al poder a la Unidad Popular a fines de 1970, y en los primeros meses del nuevo gobierno. Sin embargo, el tono más moderado que adoptó la serie de espionaje no pudo revertir la abrupta interrupción de la serie en abril de 1971. Por entonces, la nueva empresa del Estado, la recién creada Editorial Quimantú, había absorbido completamente el Departamento de Historietas de Zig Zag, tras una negociación que le permitió a esta última conservar sus derechos sobre otros títulos.

Quimantú no demoró en aplicar una nueva política sobre las revistas de historietas, que algunos intelectuales de izquierda venían anunciando desde antes: frenar lo que consideraban un mecanismo de penetración ideológica de efectos nefastos para el proceso que estaba viviendo el país. Las dos publicaciones más leídas, 007 James Bond y El siniestro Doctor Mortis, fueron las primeras en verse afectadas, aunque finalmente todos 
los restantes títulos comenzaron a ser evaluados bajo el nuevo criterio. ${ }^{32}$

Así terminó el experimento de publicar en Chile la serie inglesa, con dibujantes y guionista chilenos. En el ambiente polarizado de 1971 poco importaba que el contenido tuviera ciertos componentes que lo habían distanciado del modelo original, aunque sin alejarse completamente del formato propio de las series de espionaje. Los efectos de la Guerra Fría se hacían sentir en el país y con ello se impuso el debate sobre la importancia de enfrentarse también en el plano de la cultura. Aunque no toda la izquierda compartiera el mismo diagnóstico, en este caso en particular se impuso la suspensión de la publicación por parte de la editorial estatal. ${ }^{33}$

\section{Conclusiones}

Chile no estuvo ajeno al ambiente típico de confrontación que caracterizó a la Guerra Fría, cuyo impacto estuvo determinado por factores internacionales y nacionales. En el primer caso, fue importante la acción desplegada por ambos bloques, la influencia de las agencias noticiosas y la cultura de masas que asediaba de múltiples formas, a través de libros, películas e historietas de origen extranjero. También influyeron los factores internos, vinculados a una larga rivalidad entre la derecha y la izquierda, así como desconfianzas y diferencias estratégicas dentro de esta última. Sin embargo, también hubo posiciones políticas que intentaron tomar distancia de ambos bloques, como fueron varias propuestas de reformismo nacionalista.

Es necesario tener en cuenta que la Guerra Fría en el campo de la cultura contó con exponentes de ambos bandos. Es decir, no solo circularon contenidos anticomunistas en revistas como Okey. En ella también hubo simpatías por los republicanos españoles, la lucha antifascista de la guerrilla en Francia y la intervención soviética durante la Segunda Guerra Mundial. Del mismo modo, es posible detectar series donde se formulaban críticas a la falta de democracia en Estados Unidos.

En todo caso, es claro que hubo mayor presencia de contenido anticomunista. La serie James Bond fue una de ellas, con alusiones frecuentes a la amenaza roja. En la primera publicación en Chile de la serie inglesa, que circuló entre 1959 y 1964, el lenguaje intentó ser suavizado, eliminándose el exceso de referencias a los soviéticos. En su reemplazo se utilizaron eufemismos como "potencia extranjera", que no impedían entender a qué país se refería el guión, ya que la trama misma lo aclaraba. Es posible que la situación interna del país, con ciclos de mayor tolerancia política, haya colaborado a atenuar la dureza del lenguaje y evitar críticas que afectaran su nivel de venta.

\footnotetext{
${ }^{32}$ La revista El siniestro Doctor Mortis se vio afectada en su contenido y finalmente su creador, Juan Marino, la comenzó a publicar en otra editorial. Manuel Jofré, "Las historietas y su cambio. Experiencias prácticas para la transformación de los medios en el proceso chileno", en Ariel Dorfman y Manuel Jofré, Superman y sus amigos del alma, Editorial Galerna, Buenos Aires, 1974.

${ }^{33}$ Sobre este, puede consultarse Rojas, Las historietas en Chile, 1960-1980.
} 
En los años 60, el contexto comenzó a variar, al diluirse la polaridad que había forzado a cerrar filas en torno a los dos bloques. En la nueva versión de la serie James Bond, esta vez dibujada en Chile y recreada con historias nuevas, algunos episodios mantuvieron un contenido anticomunista. Sin embargo, la tendencia fue a que la moderación aumentara. El ambiente de mayor distensión favoreció este cambio, sumado al hecho de que la producción fuera nacional, lo que permitió una mayor intervención sobre los contenidos.

A diferencia de las novelas y de la versión en cómics publicada entre 1959 y 1964, la que circuló entre 1968 y 1971 tuvo contenidos más livianos y de menor intensidad política, aunque también hubo otros más clásicos. Por ejemplo, se agregaron otros enemigos, además de los comunistas, y en algunos casos los servicios ingleses y soviéticos aparecieron colaborando, algo que algunas series para televisión también habían incorporado. Adicionalmente, las conquistas amorosas, el énfasis en la acción y el erotismo de algunas escenas aumentaron en esta versión.

Aunque la Guerra Fría fue común a lo largo de todo el período de estudio, alcanzando momentos especialmente intensos, en los años 60 la oposición cerrada y permanente entre ambos bandos se fue diluyendo, abriendo camino a un ambiente de mayor distensión. La apertura de relaciones diplomáticas, los quiebres dentro de los dos bloques y las estrategias favorables a la coexistencia pacífica colaboraron en esa dirección. Esto se pudo observar si comparamos las dos versiones para cómics de la serie James Bond que circularon en Chile. La primera se ajustó más al original inglés, con ligeros cambios en el diseño y algún nivel de intervención sobre el texto, que eliminó la abundancia de referencias directas al comunismo. En la segunda versión, la injerencia fue mucho mayor, ya que se trataba de una revista con dibujantes locales y un guión que adaptaba el contenido de las novelas y creaba capítulos inéditos.

Los estudios sobre el cómic no suelen ahondar en la forma en que las obras originales y las reproducciones y adaptaciones han circulado. La tendencia predominante es a estudiar lo peculiar de cada país, relegando a un segundo plano las historietas extranjeras, que se suponen una mera réplica del original. La internacionalización de la cultura de masas no ha logrado ser comprendida en toda su complejidad, con peculiares formas de integración (y tensión) entre lo local y lo global.

En los cómics analizados se observa que la Guerra Fría fue un proceso de gran influencia en el mundo, penetrando con facilidad en el espacio de la entretención, aunque la recepción no haya sido mecánica ni pasiva, como podría observarse a primera vista. Por diversos factores, el contenido fue afectado por la realidad local, en distintos grados, y el resultado fue una síntesis peculiar, donde las fronteras entre lo propio y lo ajeno se diluyeron. A partir de esta investigación es posible apreciar el potencial que tiene la historieta para hacer un seguimiento del alcance y las peculiaridades del discurso anticomunista en una sociedad como la chilena, así como de otros contenidos afectados por dinámicas propias de la cultura de masas. 
Obras citadas

Libros y artículos:

Alburquerque, Germán: La trinchera letrada. Intelectuales latinoamericanos y Guerra Fría, Santiago: Ariadna Ediciones, 2011.

Barker, Martin: Comics: ideology, power and the critics, Manchester/New York: Manchester University Press, 1989.

Black, Jeremy: The Politics of James Bond: From Fleming's Novels to the Big Screen, Westport: Praeger Publishers, 2001.

Black, Jeremy: "The Geopolitics of James Bond", Intelligence and National Security, 19.2 (Summer/2004), 290-303.

Calandra, Benedetta, y Marina Franco (eds.): La guerra fría cultural en América Latina. Desafíos y límites para una nueva mirada de las relaciones interamericanas, Buenos Aires: Biblos, 2012.

Casals Araya, Marcelo: Anticomunismos, política e ideología en Chile: la larga duración de la "campaña del terror" de 1964, tesis de Magister en Historia, Pontificia Universidad Católica de Chile, Santiago, 2012.

Chapman, James: Licence to Thrill: A Cultural History of the James Bond Films, New York: Columbia University Press, 2000.

Dodds, Kalus: "Screening Geopolitics: James Bond and the Early Cold War films (19621967)", Geopolitics, 10.2 (2005), 266-289.

Eco, Humberto: Apocalípticos e integrados en la cultura de masas, Barcelona, Ediciones Lumen, 1965.

Estefane, Andrés: "De naufragios e infortunios. Louis Antoine Vendel-Heyl en Chile", en Juan Luis Ossa y otros, XIX Historias del siglo diecinueve chileno, Santiago: Ediciones B, 2006, 71-98.

Garay, Cristián, y Ángel Soto: Gabriel González Videla, No a los totalitarismos, ya sean rojos, pardo o amarillos, Santiago: Centro de Estudios Bicentenario, 2013.

García, Mauricio: "Germán Gabler" (entrevista), disponible en el sitio web Ergocomics: http://ergocomics.cl/wp/2003/11/germn-gabler/

Gómez Leyton, Juan Carlos: La frontera de la democracia. El derecho de propiedad en Chile 1925-1973, Santiago: Lom Ediciones, 2004. 
Huneeus, Carlos: La Guerra Fría Chilena. Gabriel González Videla y la Ley Maldita, Santiago: Debate, 2009.

Janello, Karina C.: "El Congreso por la Libertad de la Cultura: el caso chileno y la disputa por las "ideas fuerza" de la Guerra Fría", Izquierdas, 14 (dic./2012), 14-52.

Jofré, Manuel: "Las historietas y su cambio. Experiencias prácticas para la transformación de los medios en el proceso chileno", en Ariel Dorfman y Manuel Jofré, Superman y sus amigos del alma, Editorial Galerna, Buenos Aires, 1974.

Maldonado, Carlos: ACHA y la proscripción del Partido Comunista en Chile, 1946-1948, Santiago: Flacso, marzo/1989.

McCloud, Scott: Understanding Comics: The Invisible Art, Northampton: Kitchen Sink Press, 1993.

MacDougall, Robert: "Red, Brown and Yellow Perils: Images of the American Enemy in the 1940s and 1950s", The Journal of Popular Culture, 32.4 (1999).

Montealegre, Jorge: Historia del humor gráfico en Chile, Lleida: Editorial Milenio, 2008.

Muro Munilla, Miguel Ángel: Análisis e interpretación del cómic. Ensayo de metodología semiótica, Logroño: Universidad de La Rioja, 2004.

Murray, Christopher: Champions of the Oppressed? Superhero Comics, Popular Culture, and Propaganda in America During World War II, New Jersey: Hampton Press, 2011.

Payás, Gertrudis: "La Biblioteca Chilena de Traductores, o el sentido de una colección", en Biblioteca chilena de traductores ordenada por José Toribio Medina, 2da edición, Santiago: Dirección de Bibliotecas, Archivos y Museos, 2007, pp.23-68.

Pedemonte, Rafael: "La 'diplomacia cultural' soviética (1964-1973)", Bicentenario, 9.1 (2010), 57-100.

Petra, Adriana: "Cultura comunista y Guerra Fría: los intelectuales y el movimiento por la paz en la Argentina", Cuadernos de Historia, 38 (junio/2013), 109-130.

Rojas Flores, Jorge: "Estrategias de poder y valores políticos en Mampato (1968-1978)", Mapocho, 71 (1er semestre/2012), 297-314.

Rojas Flores, Jorge: "Luchas políticas en una revista de historietas: Okey, 1949-1965", Cuadernos de Historia, 40 (junio/2014), 115-145.

Rojas Flores, Jorge; y Mauricio García: "Humor, magia y política en El Diario Ilustrado: el caso de Chu-Man-Fú (1938-1950)”, Mapocho, 76 (2do semestre/2014), 219-242. 
Rojas Flores, Jorge: Las historietas en Chile, 1960-1980. Industria, discursos y prácticas sociales, Santiago: Lom Ediciones, 2015 (en edición).

Rojas Flores, Jorge. "Tiranías, luchas políticas y justicia en una revista chilena de historietas: Okey, 1949-1965”, inédito.

Rojas Flores, Jorge. “Imágenes de la mujer en Okey, 1949-1965”, inédito.

Salinas, Maximiliano; Jorge Rueda, Tomás Cornejo y Judith Silva: El Chile de Juan Verdejo. El humor político de Topaze, 1931-1970, Santiago: Editorial USACh, 2011.

Tornabuoni, Lietta; Oreste del Buono; Humberto Eco y otros: Proceso a James Bond. Análisis de un mito, Barcelona: Editorial Fontanella, 1965.

Sitios web:

Comiclopedia, de Lambiek: http://www.lambiek.net

Toonopedia: http://www.toonopedia.com

Tebeosfera: http://www.tebeosfera.com

Archivo 007: http://www.archivo007.com

The Home of James Bond 007: http://www.mi6-hq.com.

Revistas y libros de historietas:

007 James Bond, Editorial Zig Zag, 59 números, 1968-1971.

The James Bond Omnibus, Titan Books, volume 001, 2009.

Okey, Editorial Zig Zag, 850 números, 1949-1965.

Recibido: 10 abril 2015 Aceptado: 13 mayo 2015 